\title{
A ESCOLA FAMÍlIA AGRÍCOLA TABOCAL E A EDUCAÇÃO PROFISSIONAL PARA O CAMPO
}

\section{Resumo}

\author{
Vanessa Clarinda Apolinário ${ }^{1}$ \\ Maria Aparecida Colares Mendes ${ }^{2}$
}

DOI: https://doi.org/10.36524/profept.v5i2.770

A Escola Família Agrícola Tabocal oferta educação profissional para o campo, o desenvolvimento sustentável da região norte mineira e o fortalecimento da agricultura familiar. O que pressupõe uma formação humana integral e cidadã. Dessa forma, este artigo objetiva caracterizar e analisar a referida Escola, buscando responder se esse educandário promove uma formação integral contribuindo para a ampliação da cidadania na educação profissional? Pautamos essa reflexão em pesquisa bibliográfica e de campo. Concluímos que, as pretensões educativas da Escola possuem embasamento no movimento histórico dos campesinos por uma educação que atenda aos seus anseios, e que, a manifestação dessas pretensões no processo de ensino-aprendizagem ocorre carregada de tensões, desafios e avanços.

Palavras-chave: Escola Família Agrícola; educação profissional; educação do campo.

\section{THE TABOCAL FAMILY AGRICULTURAL SCHOOL AND PROFESSIONAL EDUCATION FOR THE FIELD}

\begin{abstract}
The Escola Agrícola Tabocal School offers professional education for the countryside, the sustainable development of the northern region of Minas Gerais and the strengthening of family farming. Which presupposes an integral human and citizen formation. Thus, this article aims to characterize and analyze the said School, seeking to answer whether this student promotes comprehensive education contributing to the expansion of citizenship in professional education? We base this reflection on bibliographic and field research. We conclude that the educational pretensions of the School are based on the historical movement of the peasants for an education that meets their desires, and that the manifestation of these pretensions in the teaching-learning process is fraught with tensions, challenges and advances.
\end{abstract}

Keywords: Agricultural Family School; professional education; rural education.

\footnotetext{
${ }^{1}$ Instituto Federal de Educação Ciência e Tecnologia do Norte de Minas Gerais. E-mail: apolinariovvc@gmail.com

${ }^{2}$ Instituto Federal de Educação Ciência e Tecnologia do Norte de Minas Gerais. E-mail: cidacolares@ hotmail.com
} 


\section{INTRODUÇÃO}

A Escola Família Agrícola Tabocal - EFA Tabocal, surgiu no ano de 2004 no semiárido norte mineiro, como possibilidade para a formação das pessoas que vivem no campo, tendo como inspiração a experiência das Escolas Famílias Agrícolas desenvolvidas pelo mundo. Buscando amalgamar-se ao contexto de vida dos norte mineiros que vivem no campo e tem a terra como meio de produção, aliando-se aos conhecimentos produzidos por autores que defendem a educação dos trabalhadores como bem emancipador e libertador, para superação das mazelas sociais criadas pelo modo de produção capitalista.

A EFA Tabocal oferta a educação profissional em nível técnico, por meio do Curso Técnico em Agropecuária Integrado ao Ensino Médio de Alternância, o que reflete uma conquista da classe trabalhadora do campo, em suas disputas por uma educação que atenda aos seus anseios, tendo em vista uma formação que contemple todas as dimensões do ser humano e, assim, possa ir rumo à construção de possibilidades na conquista de uma cidadania plena e emancipada.

No entanto, esse projeto lida com dificuldades para implantar plenamente sua missão educativa e de manter uma estrutura que lhe dê suporte. Pois se depara com disputas de poder, com forças que tratam a educação como produto, tendo como pressuposto uma formação que atenda ao mercado de trabalho capitalista, amplamente apoiada por instâncias governamentais nacionais e internacionais que exercem influência e poder nas políticas públicas neoliberais, que cada vez mais, reduz o papel do Estado na garantia dos direitos.

Diante do enunciado, objetiva-se neste artigo caracterizar e analisar a Escola Família Agrícola Tabocal (EFA Tabocal), que oferta uma educação profissional para o campo, buscando responder: A EFA Tabocal promove formação integral e contribui para a ampliação da cidadania na educação profissional? Essa questão pode nos auxiliar a compreender a qual projeto educacional ela atende, se é aquele para formação da classe trabalhadora dos campesinatos, que elege a formação integral do ser humano como meio de transformação da realidade, ou, ao projeto que estabelece uma formação fragmentada para conformação a uma realidade dada.

Reconhecemos que essa reflexão é importante no contexto das políticas públicas que vivemos, que consideravelmente, tem dificultado o acesso a direitos conquistados pelos 
movimentos sociais campesinos, provocando muitas vezes sua dissolução, o que requer pesquisas com um olhar atento e o peculiar rigor científico, que a elas confere credibilidade.

Para isso, realizamos uma pesquisa bibliográfica, com suporte nos autores: Araújo e Frigotto (2015) que discorrem sobre o trabalho como princípio educativo - o trabalho compreendido como produtor de cultura e de satisfação das necessidades para a conquista da liberdade; Begnani (2002, 2003 e 2019), Jesus (2011), Nosella (2014) e Silva (2015) que tratam a respeito das Escolas Família Agrícola - seus fundamentos, como a Pedagogia da Alternância, e suas mediações pedagógicas; em Grabowski e Kuenzer (2016) buscamos a compreensão da dualidade na educação profissional; a temática da cidadania plena e emancipada foi abordada de acordo com Mendes (2013) e em Moura; Lima Filho subsidiamonos para a compreensão da politecnia na educação profissional. Realizamos ainda, observações diretas e indiretas no lócus da pesquisa, bem como, leitura de documentos normativos e estruturais da EFA Tabocal, que originaram dados tratados conforme dispõe o método de análise de conteúdo para atender ao objetivo proposto.

\section{PERCURSO METODOLÓGICO}

A pesquisa foi realizada na Escola Família Agrícola Tabocal, onde é ofertado o Curso Técnico em Agropecuária Integrado ao Ensino Médio de Alternância, localizada na Fazenda Granja Primavera, Município de São Francisco - Minas Gerais, entre os meses de outubro a dezembro do ano de 2019.

Para realizá-la optou-se por uma abordagem qualitativa, que de acordo com Lüdke e André (1986), é necessária nas pesquisas que buscam compreender fenômenos educacionais, pois estes estão situados no contexto social, cuja realidade é histórica, dinâmica e complexa, exigindo do pesquisador investidura com técnicas apropriadas na realidade estudada para reflexão sobre o que, de fato, possa responder adequadamente ao problema.

Optou-se ainda, por uma revisão bibliográfica, que como afirma Alves-Mazzotti (2002), permite situar o problema da pesquisa no tema proposto e analisar o que a literatura construída na área fundamenta do quadro teórico da pesquisa. Que neste estudo tem por autores Nosella (2014) que discorre sobre a história das EFAs no mundo, seu surgimento e difusão no Brasil, bem como, de sua organização nos pilares da Pedagogia da Alternância, formação integral, Associação e desenvolvimento sustentável. Begnani (2002, 2003 e 2019) e Silva (2015), que nos informam sobre a Pedagogia da Alternância, o sistema e metodologia 
que dela se origina e como é utilizada nas Escolas Famílias Agrícolas. Moura; Lima Filho; Silva (2015), no que se referem ao trabalho como princípio educativo na politecnia e omnilateralidade. Grabowski e Kuenzer (2016), que elucidam sobre a dualidade estrutural da educação no Brasil. Mendes (2013), que discute o conceito cidadania plena e emancipada e Araújo e Frigotto (2015), que tratam das práticas pedagógicas para o ensino médio integrado.

Como procedimento de coleta de dados, foram realizadas observações diretas e indiretas com 22 educandos e oito educadores, de uma turma do $2^{\circ}$ ano do Curso Técnico em Agropecuária da EFA Tabocal, nos espaços e tempos escolares próprios das atividades educacionais. Que foram registradas em diários de campo, procedimento e instrumento de pesquisa que permitem aproximação e verificação das perspectivas dos sujeitos pesquisados, bem como, descrição e reflexão do conteúdo observado (LÜDKE E ANDRÉ, 1986).

Associado ao procedimento de observação, foram coletados dados em documentos normativos como Regimento, Proposta Político Pedagógica, Proposta Eco-Político Pedagógica e Estatuto da Associação Escola Família Agrícola do Vale do São Francisco; documentos administrativos estruturais como, os escriturados em livros e fichas de matrícula e diários de classe; documentos didáticos pedagógicos, como o caderno da realidade e plano de estudo; e ainda, em documentos legais, a saber, Leis, Pareceres, Portarias e Decretos que regem especificidades do funcionamento das Escolas Famílias Agrícolas.

Os dados foram analisados por meio da classificação das informações que importam ao tema, objetivo e problema da pesquisa, relacionados aos procedimentos utilizados pela EFA Tabocal, seu funcionamento, sua estrutura física e humana, respaldando-nos na análise de conteúdo, que, de acordo com Bardin (2010, p. 9), é "um conjunto de instrumentos metodológicos" aplicados a análise de dados de naturezas diversas.

Ressalta-se que, os dados usados neste artigo fazem parte dos dados que foram coletados em uma pesquisa mais abrangente, a do Mestrado Profissional em Educação Profissional e Tecnológica do Programa Nacional de Pós-Graduação.

\section{RESULTADOS E DISCUSSÕES}

\section{Escola Família Agrícola: surgimento e intenções}


A vida de homens e mulheres na roça, no campo, trabalhando com a terra, por meio da agricultura, fora vista por muitos como despotencializada de conhecimentos e cultura, lugar de laboro sofrido, esquecido por governos e governantes, como ilustrou Monteiro Lobato na obra Urupês em $1914^{3}$. Ao personificar o homem que trabalhava no campo com o Jeca Tatu, um caboclo, caipira que sofre pelas mazelas sociais e econômicas geradas pelas "violentas relações de poder nas quais muitas culturas são silenciadas", pela ausência de políticas públicas que respeitem identidades, territórios, saberes e culturas (ROQUE, 2017. pág. 25).

A gênese e evolução dessas relações de poder, derivam das consequências do modo de produção, desenvolvimento econômico capitalista e da divisão social de classes, cujos impactos gerados na educação refletem nos projetos educacionais e nos objetivos de formação humana que eles preconizam, o que leva às disputas de interesses.

Desse modo, esses projetos podem ser para a conformação humana, a realidade dada com um ensino de "fragmentos da cultura sistematizada", em que pesam práticas da pedagogia das competências ${ }^{4}$, que pode gerar a submissão humana a modos de vida precários, excludentes e limitados dentro de um ciclo de violência e exploração (ARAÚJO; FRIGOTTO, 2015, p. 62).

No entanto, esses projetos podem também estar a serviço da transformação da realidade e para isso, objetivam formar integralmente o ser humano, desenvolvendo suas capacidades intelectuais, físicas, criativas, cognitivas, políticas, dentre outras. Conduzindo-os a cidadania plena e emancipada, em que participe consciente e criticamente de ações que garantam a liberdade, solidariedade, sustentabilidade, vida digna, respeito as diferenças, à natureza em âmbito individual e coletivo (MENDES, 2013).

Uma educação que comporta o desenvolvimento pleno do ser humano requer práticas pedagógicas com estratégias didáticas e compromisso ético-político, que integrem "teoria e prática, ensino técnico e profissional, no ensino médio, sendo essencial vincular o ensino ao trabalho real dos alunos" (ARAÚJO; FRIGOTTO, 2015, p.61).

A formação integral compõe o objetivo principal do projeto de educação, que os povos que vivem no campo elegeram para expressar, e buscar, em suas disputas e resistência, educação que transforme suas vidas. A expressão dessas disputas e resistências iniciou com

\footnotetext{
${ }^{3}$ Como escritor, Monteiro Lobato utiliza o personagem Jeca Tatu para discutir questões sociais e fazer crítica à elite intelectual brasileira da época, que permanecia cega a situação dos trabalhadores rurais. (MOREIRA, 2010)

${ }^{4}$ Pedagogia das Competências é definida por estratégias, objetivos e conteúdos de ensino que servirão a bases produtivas no trabalho sob o modo de desenvolvimento capitalista. (RAMOS, 2012).
} 
um pequeno grupo de camponeses e clérigos da Igreja Católica em 1935 na França, onde criaram, de forma incipiente e intuitiva, a primeira Escola Família Agrícola, pois muitos agricultores e seus filhos não queriam deixar suas terras e suas famílias indo para as cidades para dar continuidade aos estudos. Mas sabiam que não poderiam deixar de aprender a cultura geral para além do que seu modo de vida os propiciava (NOSELLA, 2014).

Nas primeiras Escolas Famílias Agrícolas criadas, os jovens agricultores estudavam um período do mês, geralmente uma semana, na paróquia da Igreja com um padre que lhes ensinava aspectos elementares da cultura geral e técnicas para aprimorar a agricultura, mas sem um currículo ou programa de ensino formal. Nesse período, os jovens, além de estudar, deveriam cuidar de aspectos relacionados a sua estadia no local, como preparo de refeições, limpeza, descanso, pois não voltavam para as suas casas dia a dia após os estudos (NOSELLA, 2014). No restante do mês, os jovens ficavam em suas casas e propriedades agrícolas, compartilhando com os demais membros de sua família o que haviam aprendido, aplicando novas técnicas no trabalho no campo.

A experiência educativa por que passara aqueles jovens agricultores na França, nas Escolas Famílias Agrícolas, foi nomeada de Pedagogia da Alternância (PA), que de acordo com Nosella (2014, p. 29), é uma "forma de organizar o processo de ensino-aprendizagem alternando dois espaços diferenciados: a propriedade familiar e a escola".

A experiência francesa evoluiu, possibilitando a ampliação da oferta das Escolas Famílias Agrícolas (EFAs) por toda a França, estendendo-se à Itália, país de onde vieram as primeiras experiências para a criação de Escolas Famílias Agrícolas no Brasil, precisamente no Estado do Espírito Santo no ano de 1969 (NOSELLA, 2014).

As primeiras EFAs foram se desenvolvendo e transformando-se em Instituições vigorosas, da oferta de ensino informal, até chegar na oferta de educação profissional integrada ao ensino médio no ano 2000 aqui no Brasil (BEGNAMI, 2003). As EFAs também se expandiram em termos territoriais, após a experiência pioneira no estado do Espírito Santo, foram instaladas EFAs no Estado da Bahia e Amazonas, em seguida foram nos Estados do Ceará, Piauí, Maranhão, Rio Grande do Norte, Rondônia, Amapá, Goiás, Santa Catarina e Minas Gerais (NOSELLA, 2014).

Em Minas Gerais, segundo a Associação Mineira das Escolas Famílias Agrícolas (AMEFA), a implantação das primeiras experiências de escolarização em conformidade com a Pedagogia da Alternância esteve relacionada com o movimento social e eclesial no final dos anos 70 e início dos anos 80. Essa foi uma época de reestruturação e/ou criação de vários 
Sindicatos de Trabalhadores Rurais e formação de vários outros movimentos de organização dos agricultores na luta pela terra e na tentativa de reação da agricultura familiar ao processo de submissão da exploração agrícola ao capital internacional (SOUZA, 2016, pág. 4).

O detalhamento da AMEFA revela que, as EFAs brasileiras também estiveram ligadas a movimentos de luta por direitos sociais imprescindíveis a vida humana, que foram negligenciados à população que vive no campo, fatos que são similares na criação de cada Escola Família Agrícola pelo mundo.

\section{A Escola Família Agrícola Tabocal: intenções e ações a partir da análise dos documentos regulatórios}

Os movimentos e interlocuções tratados na criação da primeira EFA na França, ganharam eco e se repetiu fazendo-se sentir e refletir, sessenta anos depois, na criação da Escola Família Agrícola Tabocal - EFA Tabocal, lócus dessa pesquisa, no semiárido norte Mineiro, no ano de 2003, possibilitando a instalação de uma EFA na Fazenda Tabocal ${ }^{5}$, área rural do Município de São Francisco, mantida pela Associação das Escolas Famílias Agrícolas do Vale do São Francisco - AEFAV e vinculada a Associação Mineira das Escolas Famílias Agrícolas - AMEFA.

A Escola Família Agrícola Tabocal é resultado de uma mobilização de agricultores familiares, lideranças comunitárias, sindicais, Cáritas Diocesana de Januária ${ }^{6}$, associações, pessoas e entidades comprometidas e preocupadas com o desenvolvimento Sustentável da Região. [...] com a finalidade de ministrar o Curso Técnico em Agropecuária Integrado ao Ensino Médio de Alternância [...] (PROJETO POLÍTICO PEDAGÓGICO DA EFAT, 2015, P. 03 E 04)

\footnotetext{
${ }^{5}$ A Escola Família Agrícola Tabocal, inicialmente funcionou na Fazenda de mesmo nome, mas mudou de endereço no ano de 2011, para a Fazenda Granja Primavera (PORTARIA No 95412011), local onde possui melhores condições estruturais e de acesso para ofertar a modalidade de educação profissional com as especificidades da alternância. Permaneceu com o nome Tabocal em agradecimento às pessoas do Povoado e Fazenda que possibilitaram sua instalação no Município de São Francisco-MG.

${ }^{6}$ Criada em 12 de novembro de 1956, a Cáritas Brasileira é um organismo de pastoral social da Conferência Nacional dos Bispos do Brasil e integra a Comissão para a Caridade, a Justiça e Paz (comissão 8) da CNBB. É entidade de assistência social. Sua ação é ecumênica, dentro e fora da comunidade eclesial, estabelecendo parcerias com organismos nacionais e internacionais pela defesa da vida e dos direitos fundamentais da pessoa. (POLETO E ADAMS, 2005).
} 
A EFA Tabocal, além de Escola, é uma propriedade agropecuária onde se plantam diferentes espécimes e cria-se animais. Como educandário particular, sem fins lucrativos e unidade de produção agropecuária de uma associação de famílias agricultoras, a renda angariada do trabalho dos membros e seus filhos nessa propriedade é comunitária e cooperativa, o que contribui para a manutenção do projeto escolar e da estadia dos educandos quando estão na Escola, no que denomina-se de sessão escola. Como não é suficiente para manutenção de toda a infraestrutura da Escola, conta-se também com recursos públicos do Governo Estadual e Federal, angariados via convênios (BRASIL, 2012)

A EFA Tabocal matriculou no ano de 2019 mais de 100 pessoas na faixa etária dos 16 (dezesseis) aos 30 (trinta) anos de idade, que residem em São Francisco, Minas Gerais e em outros municípios do norte desse Estado, Icaraí de Minas, Januária, Ubaí, Luizlândia, Brasília de Minas, Japonvar, Lontra, Montalvânia, Mirabela, Manga, Bonito de Minas, São João das Missões, Pintópolis, Urucuia e Chapada Gaúcha (LIVRO DE MATRÍCULA EFA TABOCAL, 2019).

Os educandos da EFA Tabocal são, em sua maioria, provenientes de campesinatos, que na descrição de Costa e Carvalho (2012), se traduz num conjunto de famílias que existem em territórios caracterizados por biomas e ecossistemas específicos de onde produzem seu sustento. E por aspectos culturais próprios, geralmente são identificadas pelo seu modo de vida, suas histórias e seus saberes, sendo chamados de Quilombolas, Indígenas, Geraizeiros, Vazanteiros, Pescadores, Ilheiros, Ribeirinhos, Campesinos, Agricultores Familiares, dentre outros.

\section{Quadro 1- Distribuição dos educandos da EFA Tabocal por local de residência}

\begin{tabular}{|l|l|l|}
\hline \multicolumn{1}{|c|}{ Conjunto de Dados } & Valor absoluto & Porcentagem \% \\
\hline Sítio ou fazenda & 103 & $58 \%$ \\
\hline Povoado/Distrito/Vila & 25 & $14 \%$ \\
\hline Cidade & 20 & $11 \%$ \\
\hline Comunidade remanescente de Quilombo & 18 & $10 \%$ \\
\hline Comunidade Indígena & 12 & $7 \%$ \\
\hline
\end{tabular}

Fonte: Formulários de matrícula dos educandos da EFA Tabocal - Ano de 2019.

Observa-se no quadro 1 que a maioria dos educandos da EFA Tabocal residem em territórios caracterizados como do campo e de pessoas que estão em movimentos em defesa de suas identidades e cultura. Mesmo os $25 \%$ (vinte e cinco por cento) que residem em cidades, distritos, vilas e povoados possuem "interesse no desenvolvimento rural através da 
educação em Alternância", o que é comprovado pelo seu cadastro, ou de seus responsáveis, na Associação que mantém a EFA Tabocal (ESTATUTO DA ASSOCIAÇÃO EFA DA REGIÃO DO VALE DO SÃO FRANCISCO, 2017, p. 4).

Pode-se compreender, por meio dos documentos analisados, em relação a EFA Tabocal que desde sua criação, implementação e sustentação, ao longo dos anos, o processo é resultado da luta e resistência que são empreendidas contra a opressão, causada por um modelo educacional que visa o desenvolvimento parcial do trabalhador, excluindo parcelas de pessoas que vivem no campo em ter acesso a uma educação que dê sentido a sua vida no lugar onde vivem e promova o seu pleno desenvolvimento, o que é bem diferente do projeto de uma educação que atende somente aos da classe social burguesa, que dispõe de recursos variados para promover seu projeto.

A diferença que existe na educação das classes sociais no Brasil, em todos os níveis e modalidades, já foi denunciada. Grabowski e Kuenzer (2016) a definem como dualidade estrutural na educação, sentida com maior precisão no ensino médio e educação profissional, que de um lado oferta educação de base tecnológica, sócio histórica e científica à elite, o que a favorece na compreensão e ação sobre as demais classes sociais. E relega aos trabalhadores uma educação de base superficial, de conceitos, elementos, habilidades e capacidades primárias e gerais que os subordinam aos meios e métodos de produção capitalista comandada pela elite.

A EFA Tabocal, busca a superação dessa dualidade, ao dispor que sua missão é a “[...] formação integral da pessoa e o desenvolvimento rural sustentável [...], na perspectiva da Agricultura Familiar, da Segurança Alimentar e Nutricional e da Agroecologia” (PPP - EFAT, 2015, p. 4 e 19). Objetivos que se conectam ao ideal de uma educação crítica que emancipe social, política e economicamente as pessoas, à cidadania plena e emancipada que possibilite a valorização do ser humano, seu território, sua história, seu saber, sua cultura, o seu modo de fazer e aprender sobre as coisas para uma transformação que vise o bem comum, com uso responsável e sustentável do meio em que vivemos (MENDES, 2013).

Nota-se ainda, que o projeto educacional da EFA Tabocal tem por missão superar desafios pelo objetivo e compromisso que tem com a formação cidadã, que nas palavras de Mendes $(2013$, p.183, 184) não é para uma cidadania "prescritiva de direitos e de deveres, voltada para os ditames normativos e legais previstos no estado de direito", mas para a "cidadania plena e emancipada". Plena porque rompe com a ideia de fragmentação, em que 
importa o todo "estruturado e dialético" e emancipada porque é no "princípio da liberdade" que as escolhas são realizadas visando o bem comum e a "satisfação pessoal", sendo basilar para conquista dessa cidadania a participação, elevação da escolaridade, autonomia e inserção no mundo do trabalho, o que na EFA Tabocal vincula-se nos quatro pilares que sustenta seu projeto educativo, que são

Associação como princípio da participação e do desenvolvimento das famílias, [...] meio de responsabilizar-se pelo Plano de formação da Escola e pela gestão [...]. A Alternância como princípio metodológico ${ }^{7}$, como a estratégia da ação pedagógica mais eficaz e mais apropriada à realidade do campo e da profissionalização dos jovens rurais; A formação integral da pessoa como uma das principais metas da ação educativa; Desenvolvimento Rural Sustentável, a educação sozinha não transforma o meio, porém sem ela se torna impossível qualquer transformação[...]. (PPP, 2015, P 12).

A metodologia que singulariza o processo educativo na EFA Tabocal, a da alternância, posiciona o trabalho como princípio educativo, que conforme declara Marx (1984), apud Moura; Lima Filho; Silva, (2015), o trabalho é para o ser humano uma necessidade que gera a liberdade, no que o reconhece como um dever, pois todos têm que colaborar na produção da vida (reino da necessidade) e é também um direito, pois todos, como iguais, precisam usufruir dos benefícios do trabalho de forma plena e digna (reino da liberdade).

[...] neste sentido, o Plano de Formação que organiza o currículo, deverá cuidar para integrar educação e trabalho, ainda mais que o público beneficiário se encontra em estado de trabalho, sobretudo de trabalho no campo. Por isso a formação deverá articular conteúdos vivenciais, com conteúdo da formação geral. (PROJETO ECO-POLÍTICO PEDAGÓGICO EFAT, 2016, p. 30)

O diálogo e a pesquisa na EFA Tabocal são ações que conduzem ao questionamento e a compreensão da realidade, como propõe Paulo Freire, que influenciou na compreensão da educação nas EFAs e, ainda hoje, seus estudos proporcionam fundamentação para esses educandários. Conforme identificou Nosella (2014, p. 31), "a mobilização do campo nos últimos anos tem conduzido as Escolas da Família Agrícola a adotar orientações pedagógicas

\footnotetext{
7 [...] o aluno alterna períodos de aprendizagem na família, em seu próprio meio, com períodos na escola, estando esses tempos interligados por meio de instrumentos pedagógicos específicos, pela associação, de forma harmoniosa, entre família e comunidade e uma ação pedagógica que visa à formação integral com profissionalização. (QUEIROZ, 2004, apud BRASIL, 2006).
} 
contra-hegemônicas, como a pedagogia libertadora, inspirada em Paulo Freire, e a pedagogia histórico-crítica”.

O ensino a partir da pesquisa da realidade, aprofunda nas ciências e volta a realidade para transformá-la [...] o processo de formação buscará romper com a educação bancária e basear-se em práticas dialógicas, visando valorizar os saberes locais dos sujeitos, os saberes das experiências feitas e construir conhecimentos na lógica da troca de saberes. (PROJETO ECOPOLÍTICO PEDAGÓGICO EFAT, 2016, p. 31 e 32)

Esses ideais são claramente defendidos por aqueles que estudam e pautam a educação profissional, como uma força que gera o desenvolvimento pleno de todas as capacidades do ser humano e a cidadania, independente de classe social, raça, religião e qualquer outro elemento que possa estereotipar e excluir pessoas.

O Crescimento em importância e em números de EFAs pela PA, gerou a necessidade de maior estruturação do processo pedagógico, com quadros teóricos, técnicos, tecnológicos e científicos que objetivavam enriquecer o processo de ensino aprendizagem. Para isso, foram criados instrumentos pedagógicos, dentre os quais o Plano de Estudo, em 1946/47 por André Duffaure, que ainda hoje é instrumento central nas EFAs (NOSELLA, 2014).

Existem outros instrumentos pedagógicos sendo utilizados nas EFAs, a exemplo na EFA Tabocal existem 11 (onze) deles, para além do Plano de Estudo.

Para que haja, de fato, continuidade de aprendizagem na descontinuidade de atividades e de espaços e tempos são utilizados instrumentos pedagógicos específicos tais como: Plano de Estudo, Colocação em Comum, Caderno da Realidade, Viagens e Visitas de Estudo, Intervenções Externas, Caderno Didáticos, Atividades de Retorno e Experiências, Projeto Profissional do Jovem, Visitas às Famílias e Avaliações. (REGIMENTO EFAT, 2015, p.12).

As EFAs podem se utilizar de outros instrumentos pedagógicos, além dos citados, e até mesmo, ressignificar os existentes (BEGNANI, 2019), o que dependerá do seu contexto e conjuntura vivida.

O Plano de Estudo na EFA Tabocal se mostrou como um dos principais instrumentos pedagógicos utilizados, acompanhado do caderno da realidade. No Plano, os educandos e educadores estabelecem os temas geradores ${ }^{8}$ que são registrados no caderno da realidade e pesquisados por meio de observações, questionamentos e experimentação com a aplicação de

\footnotetext{
${ }^{8}$ É um elemento, um conteúdo da realidade vivida, expressado em diálogos para utilização na educação como princípio para construção do conhecimento. (FREIRE, 1987)
} 
conceitos e técnicas para testar hipóteses. Os dados dessas pesquisas também são registrados no caderno da realidade.

As pesquisas são realizadas nas sessões escola, tempo em que o educando fica na EFA Tabocal; sessão comunidade, tempo em que o educando fica em casa, na comunidade e propriedade onde vive e trabalha; nas visitas técnicas e estágios. Em cada Sessão Escola os dados que os educandos coletam são socializados e discutidos em um momento que é denominado na PA de colocação em comum, caracterizado como instrumento pedagógico da PA, e dessas discussões resultam uma síntese por turma, grupo de educandos de um determinado ano/nível de ensino.

As sínteses são avaliadas pelos próprios educandos e educadores e propiciam temas para fazer apresentações artísticas, cívicas, teatrais, dentre outras e permear as discussões nos serões de estudo 9 . A maioria dos professores observados na EFA Tabocal orientam, de acordo com a especificidade de sua disciplina, como o educando vai proceder com a pesquisa.

Observa-se que existem professores que promovem a conexão dos conteúdos da disciplina que ministra, prevista na matriz curricular do curso agropecuário e diretrizes legais, tendo o tema gerador como enfoque sistematizador dos procedimentos de forma integrativa aos instrumentos pedagógicos da metodologia da alternância. Nota-se que os professores que promovem essa conexão possuem mais de cinco anos de docência na EFA Tabocal, já passaram por capacitações e possuem formação em Licenciatura em Educação do Campo.

No entanto, os professores que têm menos de três anos de trabalho na EFA Tabocal, não passaram por capacitações e tem formação em licenciaturas voltadas para áreas de formação específica, como língua portuguesa, matemática e outras. Assim como os bacharéis, que precisam de autorização para lecionar, emitidos por órgãos públicos regulatórios. Estes, de acordo com as observações realizadas, apresentam uma maior rigidez no processo de ensino ao basearem-se demasiadamente nos conteúdos de suas disciplinas previstos nas diretrizes curriculares e, ainda, pouca desenvoltura nas tratativas com os instrumentos pedagógicos da metodologia da alternância em seus tempos e espaços.

As discrepâncias vistas nas ações docentes, revelam que houve uma relação binária, que em determinados momentos escolares privilegiaram o currículo estabelecido em

\footnotetext{
${ }^{9}$ Serão de estudo é identificado na Pedagogia da Alternância como como instrumento pedagógico e se caracteriza por momentos de diálogos e apresentações artísticas que acontecem a noite nas EFAS, para representar a realidade e sua transformação. Abordam aspectos culturais e cívicos relacionados ao que se aprendeu na pesquisa de forma descontraída. (CADERNO DE ACOMPANHAMENTO DA ALTERNÂNCIA).
} 
detrimento da realidade de vida, a teoria desconectada da prática. Mas, essa relação não imperou, antes amalgamaram-se a dos educadores que atuavam para que acontecesse a alternância integrativa que possibilitava a ação-reflexão-ação, junção teoria e prática, meio de vida, trabalho e escola (SILVA, 2015).

Diante desse binômio, evidenciam-se práticas docentes para uma formação integrada, que seja crítica e transformadora. O que favorece a ampliação da cidadania, mas é evidente as limitações nessas práticas, o que favorece uma formação fragmentada que reproduz modelos sociais e desenvolvimentistas capitalistas marcados pelo "individualismo e competitividade, que violenta os princípios da emancipação e da liberdade", comprometendo a formação cidadã nos pilares que a EFA Tabocal elege como fundamentais no seu projeto educativo. (MENDES, 2013, p. 213).

Durante as observações na EFA Tabocal, ficaram nítidas as dificuldades estruturais e financeiras pela qual passa para sustentar o projeto educativo que estabeleceu como missão. $\mathrm{O}$ que exige certo grau de improviso e criatividade, que nem sempre resultam no alcance pleno dos objetivos propostos. Isso acontece, segundo informações que a Direção, Professores, Educandos e Presidente da Associação proferem, devido ao não cumprimento de convênios com entes públicos e privados, principalmente do Governo Estadual de onde provém a maior receita da EFA Tabocal, conforme determina a Lei Federal 12.695/2012 (BRASIL, 2012).

Essas dificuldades são motivos de preocupação no discurso da direção e do presidente da Associação, principalmente no que é concernente à capacitação docente, ao pagamento dos funcionários, alimentação e alojamento adequado aos estudantes e professores, aquisição de materiais, utensílios e equipamentos para desenvolver as aulas e pesquisas nas salas de aula, laboratórios, áreas de plantio e de criação de animais. Bem como de recursos para visita as famílias no tempo que o educando está na sessão comunidade. Para amenizar as dificuldades financeiras encontradas a gestão recorre a outras fontes de receita prevista no Estatuto da Associação (2017, pág. 8)

[...] contribuição social aprovado em Assembleia Geral, renda de eventos promovidos pelos associados, alunos e monitores, projetos financeiros, legados e rendas extraordinários e renda de produção da propriedade da EFA Tabocal.

A renda da produção da propriedade, a contribuição social e a renda de eventos promovidos, no momento da pesquisa, havia se intensificado, revelando-se, assim, como as 
principais fontes de receitas para manutenção da infraestrutura da EFA Tabocal, uma vez que os repasses de recursos públicos pelos Governos não aconteceram pontualmente, o que gerou vulnerabilidade no planejamento da gestão.

Essa intensificação na produção, interfere no equilíbrio da relação entre educação e trabalho na EFA Tabocal, pois quem realiza o trabalho dessa produção também são os educandos e educadores. Sendo assim, acabam por desestabilizar as estratégias didáticas pedagógicas relativas ao tempo que seria dedicado à reflexão do processo de ensinoaprendizagem, ou seja, da formação integral do educando, o que de acordo com Frigotto (2009, pág. 170), pode conduzir ao "imobilismo no plano da práxis, ponto nodal da luta de classes para a superação das relações sociais capitalistas."

Os entraves financeiros e estruturais não são exclusividades da EFA Tabocal, estão presentes em outras EFAs e desde que elas iniciaram sua atuação no mundo. Pois, o contexto de sua origem e de existência na resistência é o de marginalização de seu projeto educativo por governos que buscam atender projetos que respondem ao capitalismo, com uma formação precarizada do trabalhador, em detrimento dos projetos de emancipação do ser humano, reivindicada por esses trabalhadores (NOSELLA, 2014). O que não impede que o projeto educacional das EFAs siga evoluindo, antes o limita, exigindo cada vez mais engajamento ético e político dos que o assume, como discorrem Araújo e Frigotto (2015).

\section{CONSIDERAÇÕES FINAIS}

Ao caracterizar a Escola Família Agrícola Tabocal - EFA Tabocal - na oferta da educação profissional para o campo, pode-se depreender que ela se propõe a formação integral do ser humano para ampliação da cidadania na educação profissional, com ensino integrado, metodologia da alternância, que favorecem a conquista da autonomia e elevação da escolaridade. Com desenvolvimento rural sustentável e gestão associativa, favorecendo a participação e qualificação para inserção das pessoas no mundo do trabalho, o que é construído no diálogo daqueles que mantém o ideário da Escola, para a transformação da realidade social e econômica das pessoas, principalmente as que vivem nos campesinatos.

Isso é possível graças aos movimentos sociais, que lutam por esse projeto de educação e mantém ativo o funcionamento da EFA Tabocal. Mesmo com todas as assimetrias na aplicação das práticas pedagógicas pelos educadores, em muito originadas pelas limitações 
na formação inicial e continuada dos docentes e por questões de ordem financeira e estrutural por que passam, o que poderia ser amenizado com o repasse pontual dos recursos financeiros públicos que a EFA Tabocal tem direito pelos governantes e aperfeiçoamento das políticas públicas para formação docente.

Essas assimetrias e limitações, evidenciam que a EFA Tabocal não materializa plenamente a sua proposta de educação para formação integral e ampliação da cidadania, mas com atos de criatividade e resistência, vêm caminhando para que se consolide, enfrentando desafios, ressignificando práticas pedagógicas e reestruturando sua forma de angariar recursos para seu funcionamento.

Mediante as considerações alcançadas com este estudo, considera-se que, são importantes pesquisas sobre o financiamento público das Escolas Famílias Agrícolas, pois desde sua origem, têm apresentado impactos na sustentabilidade desses educandários e permanecem, ainda, como um ponto em desenvolvimento, e, dada sua necessidade não podem ser negligenciados, bem como, pesquisas sobre a formação inicial e continuada para professores que atuam com educação no campo e do campo, uma vez que o projeto educativo das EFAs possui singularidades de âmbitos variados, dentre eles metodológicos, que precisam ser compreendidos para serem aplicados.

\section{REFERÊNCIAS}

ALVES-MAZOTTI, A. J. A "revisão bibliográfica" em teses e dissertações: meus tipos inesquecíveis - o retorno. In: BIANCHETTI, L.; MACHADO, A. M. N. (ORG.). A bússola do escrever: desafios e estratégias na orientação de teses e dissertações. São Paulo: Cortez, 2002. P. 25-44.

ASSOCIAÇÃO MINEIRA DAS ESCOLAS FAMÍLIAS AGRÍCOLAS. Projeto EcoPolítico Pedagógico. Belo Horizonte: 2016. 158 p.

ARAUJO, R. M. De Lima; FRIGOTTO, G. Práticas pedagógicas e ensino integrado. Revista Educação em Questão, v. 52, n. 38, p. 61-80, 2015.Disponível em: <https://periodicos.ufrn.br/educacaoemquestao/article/viewFile/7956/5723 > . Acesso em: 03 maio 2020.

BARDIN, L. Análise de Conteúdo. 4 ed. Lisboa: Edições 70, 2010.

BEGNAMI, J. B. Formação por Alternância na Licenciatura em Educação do Campo: possibilidades e limites do diálogo com a Pedagogia da Alternância. 2019. 403 f. Tese 
(Doutorado em Educação) - Universidade Federal de Minas Gerais, Faculdade de Educação. Belo Horizonte, 2019.

BEGNAMI, J. B. Uma geografia da Pedagogia da Alternância no Brasil: a experiência das Casas Familiares Rurais. Brasília: UNEFAB, 2002. (Documentos Pedagógicos).

BEGNAMI, J. B. Formação pedagógica de monitores das Escolas Famílias Agrícolas e Alternâncias: um estudo intensivo dos processos formativos de cinco monitores. Belo Horizonte. 2003. 263 p. Dissertação (Mestrado Internacional em Ciências da Educação) Universidade Nova de Lisboa e Universidade François Rabelais de Tours.

BRASIL. Lei $n^{0}$ 12.695, DE 25 DE JULHO DE 2012. Dispõe sobre o apoio técnico ou financeiro da União no âmbito do Plano de Ações Articuladas e dá outras providências. Disponível em: http://www.planalto.gov.br/ccivil_03/ato2011-2014/2012/lei/112695.htm. Acesso em: 15 mai. 2020.

BRASIL. Ministério da Educação. Educação do Campo: Marcos Legais. Parecer CNE/CEB No 1 de 02 de fevereiro de 2006. Brasília, DF: SECADI, 2012, p. 39-49.

COSTA, F de, A. CARVAlHO, H. M de. Campesinato. In: Caldart, R. S.; Pereira, I. B.; Alentejano, P.; Frigotto, G. (Orgs). Dicionário Da Educação Do Campo. $2^{a}$ Ed. São Paulo: Expressão Popular, 2012.

ESCOLA FAMÍLIA AGRÍCOLA TABOCAL. Regimento Interno. São Francisco: 2015. 79 p.

ESCOLA FAMÍlia AGRÍCOLA TABOCAL. Proposta Político Pedagógica. São Francisco: 2015. 55 p.

ESCOLA FAMÍlIA AGRÍCOLA TABOCAL. Formulário de Matrícula. São Francisco: 2019.

ESCOLA FAMÍlIA AGRÍCOLA TABOCAL. Livro de Matrícula. São Francisco: 2019. p. $55-88$.

ESCOLA FAMÍlia AGRÍCOLA TABOCAL. Caderno de Acompanhamento da Alternância. São Francisco: 2019. 100 p.

ESTATUTO SOCIAL. A Associação Escola Família Agrícola da Região do Vale do São Francisco. São Francisco: 2017. 34 p.

FREIRE, P. Pedagogia do Oprimido: Paz e Terra, 1987, 23 a reimpressão. Disponível em: http: http://www.tlaxcala-int.org/upload/telechargements/150.pdf. Acesso em: 10 mai. 2020.

FRIGOTTO, Gaudêncio. A polissemia da categoria trabalho e a batalha das ideias na sociedade de classe. Rio de Janeiro: Universidade do Estado do Rio de Janeiro, Revista Brasileira de Educação, 2009, p. 168-194. 
GIMONET, Jean-Claude. Praticar e Compreender a Pedagogia da Alternância dos CEFFAs. Tradução de Thierry De Burghgrave. Petrópolis: Vozes, Paris: AIMFR Associação Internacional dos Movimentos Familiares de Formação Rural, Coleção AIDEFA, 2007.

GRABOWSKI, Gabriel; KUENZER, Acácia Zeneida. A produção do conhecimento no campo da Educação Profissional no regime de acumulação flexível. Holos, v. 6, p. 22-32, 2016. Disponível em: <http://www2.ifrn.edu.br/ojs/index.php/HOLOS/article/view/4983> . Acesso em: 05 maio 2020.

JESUS, Janinha Gerk de. Saberes e Formação dos Professores na Pedagogia da Alternância. 2011. 227 f. Dissertação (Mestrado em Educação) - Universidade Federal do Espírito Santo. Vitória/ES, 2011.

MENDES, M. A. C. Racionalidades, Cidadania e Desenvolvimento Rural: a Formação do Técnico em Agropecuária no Norte de Minas Gerais. Montes Claros 2013, 270 f. Tese (Doutorado em Desenvolvimento Rural). Universidade Federal do Rio Grande do Sul. Faculdades de Ciências Econômicas, Programa de Pós-Graduação em Desenvolvimento Rural, Porto Alegre, 2013.

MINAS GERAIS. Portaria N. ${ }^{\circ}$ 954, de 11 de agosto de 2011. Altera endereço da Escola Família Agrícola Taboca. Publicada no Diário Oficial dos Poderes do Estado de Minas Gerais de 12 de agosto de 2011.

MOREIRA, L. de S. Jeca Tatu. Disponível em: http://www.ufjf.br/graduacaocienciassociais/files/2010/11/Jeca-Tatu-parte-2-Lianna-deSouza-Moreira.pdf. Acesso em 02 de maio 2020.

MOURA, Dante Henrique, LIMA FILHO, Domingos Leite, SILVA, Mônica Ribeiro. Politecnia e Formação Integrada: Confrontos Conceituais Projetos Políticos e Contradições da Educação Brasileira. Revista Brasileira de Educação, 2015, p 1057 - 1080.

NOSELLA, P. Origens da Pedagogia da Alternância no Brasil. $2^{\mathrm{a}}$ Reimpressão. Vitória ES: EDUFES. 2014.

POLETTO, I. TELMO, A. Cáritas Brasileira Cáritas na promoção da solidariedade: como organizar a ação Cáritas / Cáritas Brasileira. - Brasília: Cáritas Brasileira, 2005. Disponível em: $\quad$ http://caritas.org.br.s174889.gridserver.com/wp-content/uploads/2011/03/cartilhac\%C3\%A1ritas-na-base-\%C3\%Baltima-vers\%C3\%A3o.pdf. Acesso em: 10 de mai. 2020.

RAMOS, M. Pedagogia das Competências. In: Caldart, R. S.; Pereira, I. B.; Alentejano, P.; Frigotto, G. (Orgs). Dicionário Da Educação Do Campo. $2^{\mathrm{a}}$ Ed. São Paulo: Expressão Popular, 2012. 
ROQUE, D. Jeca: Um Espelho do Descaso. Revista EnsiQlopédia, volume 14, número 1, Centro Universitário Cenecista de Osório - UNICNEC.out 2017, P. 25-33. Disponível em: http://sys.facos.edu.br/ojs/index.php/ensiq/article/view/15. Acesso em: 07 mai. 2020.

SILVA, L. H. A pedagogia da alternância na educação do campo: velhas questões, novas perspectivas de estudos. EccoS Revista Científica, núm. 36, gênero-abril, 2015, pp. 143-158 Universidade Nove de Julho. São Paulo, Brasil.

SOUZA, J. V. A. de. Pedagogia da Alternância: Uma alternativa consistente de escolarização rural? GT-14: Sociologia da Educação. 2016. Disponível em http://www.anped.org.br/sites/default/files/gt14-4500-int.pdf. Acesso 03 de maio de 2020. 